These are instances, which may serve to illustrate what appears to be the difference, between the wave which is permitted to break upon a slope, and that which is restrained by a wall, up which latter the vertical column of ascent may run to great heights, and yet be, comparatively and literally, a harmless firing in the air.

In conclusion, it may be observed, that although for a point, like Dover, in advance of our own shores, whereon to mount guard over the Channel, pregnant as it is with dramatic and historic interest, we may resign ourselves to incur much cost to prepare it for all that is expected of it, we cannot afford to have many Dovers. 'Time, too, is something. Cherbourg Breakwater took two generations of men to bring it even to its present state. Plymouth has already occupied more than one generation. And when the Astronomer Royal, familiar with studies of the heavenly bodies, in which "a thousand years are but as one day," tells us, that "the question of duration is between ffty and five hundred years," we feel a melancholy confirmation of the sentiment of the poet:*-

Debemur morti nos nostraque; sive receptus

Terrà Neptunus classes aquilonibus arcet,

Regis opus ;

nay, remembering Captain Vetch's projected estate of eight thousand acres on the Goodwin Sands, the rest of the passage is equally apt:-

— sterilisve diu palus aptaque remis,

Vicinas urbes alit et grave sentit aratrum.

Mr. Walker said, the Institution and the profession generally, must feel deeply indebted to Lord Lovelace, for this excellent and practical essay, on a subject demanding all the careful investigation and patient research which had evidently been bestowed upon it; and he must say, that the opinions given upon the Reports published by the Government Commissioners, whence the information had been almost entirely derided, would have done honour to any Civil Engineer of long experience. It was not the custom in this country to confer titles upon Engineers, but the Institution had now seen a Peer become, for the time, an Engineer, and in that capacity arriving at conclusions on engineering points which dis. played great critical acumen and sound judgment. It was to be regretted, that circumstances would not permit a longer time to be devored to the discussion of the Paper, as the subject was of great interest, not only to the profession, but to the nation at large.

* Vide Horatium de Arte Pocticâ. 
Before proceeding to the discussion of the purely engineering portion of the question, there was one point which should be understood, but which had not, Mr. Walker believed, been mentioned in any of the Reports. He alluded to the indifference, almost amounting to a positive objection, on the part of the mercantile shipowners, to the formation of harbours of refuge. In fact, except for avoiding the loss of human life, it was of little importance to them to diminish the present risk, or whether a ship ever arrived at its destination at all. A vessel, when freighted and on her voyage, was generally fully insured; the profit depended upon the speed with which she made the passage, and the number of cargoes she could carry in the year. She must run some risk, and carry on in all weathers, so as to arrive quickly. But the shipowners argued, that if the harbours of refuge afforded shelter, the captains would run for them under the slightest stress of weather, and that their time would be wasted; in fact, as they expressed it, "that the breakwaters and harbours of refuge would be positive nuisances," which "lazy and timid captains would convert into skulking-places."

The intention of Lord Lovelace's Paper was evidently to make a summary of the arguments for and against the various sites proposed for the harbours of refuge, and the several kinds of constructions contemplated ; criticising at the same time, the structures that had been raised in numerous situations on the coasts of Great Britain and Ireland. Mr. Walker woúld allude to two of the principal works, Plymouth and Dover, as they had been more particularly under his own direction.

The breakwater at Plymouth had been under his charge for the last ten years, and he must contend, that it could not now be considered an unstable work, although, until the materials found their own slope, it might have been expected to yield to the furious attacks of the sea, to which it was subjected.

It was a matter of history, that the original design for the Plymouth Breakwater was somewhat similar to that for Cherbourg; a long slope below low water, upon which a nearly upright wall was to be placed. In the course of the construction of the first portions of the work, after a slope above low water was adopted, Mr. Rennie and Mr. Whidby perceived, that the slope must be changed, from three to one, to five to one, and they immediately adopted the latter inclination, because they saw that the sea placed the materials at that angle. The body of the work was now so firmly consolidated, that since the last great storm, mentioned in the Paper, but little injury had been received, except at one spot, where the foreshore and the facing had suffered to some extent, in consequence of the rubble[1848.] 
stone composing the former not having been carried out to the full extent.

At the west end, Mr. Walker had advised the construction of a buttress, formed of large blocks of cut stone, built in steps, having their rise equal to the tread, and thus bringing the body to an angle of $45^{\circ}$. It was executed with peculiar care, with a vertical bond throughout, each course being tied by a dovetailed stone, into that upon which it rested. It was found, that the severest storms had never caused any disturbance of this portion of the breakwater; and he thought, if that system had been carried out more extensively, the whole structure might have required less repair than it had done.

He had carefully observed the action of the sea upon the breakwater, and he was of opinion, that the waves rose higher upon the buttress than over the long slope.

He agreed with the propriety of increasing the amount of small rubble-stone in the formation of maritime works, to fill up the interstices between the large stones, and thus to render the whole fabric as solid as possible; but he must state, that Mr. Stuart disagreed with Mr. Rendel, as to the amount of vacuity in the Plymouth Breakwater. 'The object of Mr. Walker's first visit to the Breakwater, in 1838, was to report upon the cause of the large squared stones being forced, or torn out of the surface of the upper part of the slope. He attributed it to the hydraulic pressure acting upon the under sides of the stones, when a partial vacuum was formed above them, by the passage of a wave over them. His observations of the tremendous effects of these united influences of the pressure beneath and the vacuum above, had induced him to recommend the system of filling up the vacuities with small stones, so as to render the whole body, as nearly as possible, a solid mass.

With respect to Dover, the difficulties mentioned by the authorities quoted by Lord Lovelace, did apparently exist, and perhaps it was right to examine into them; but Mr. Walker would show, that they were more apparent than real.

As to the shingle, it was true, that formerly such quantities were frequently brought into the mouth of Dover Harbour, by a gale of wind, as to render it impassable for vessels, during several tides. But the South-Eastern Railway Company, by throwing down immense masses of chalk rock and building groynes, had either stopped the progress of the shingle, or had so completely diverted it into another direction, that the Commissioners considered the bar at Dover no longer to be dreaded, and the complaint now was, that there was not enough shingle to keep up the shore and the buildings. It was 
true, that in course of time, the shingle might get round these projections ; but as the present contract, entered into by the Admiralty, was for the construction of a pier 800 feet in length, he thought, that ages might elapse, before such an accumulation of shingle could occur, as would fill up the space between the shore and the pier; and he believed, that the current having once received a direction outwards, would be prevented from again turning in-shore. In fact, the Commissioners felt so well assured of the shingle being no longer a subject of alarm, that they had a Bill before Parliament for the extension and improvement of the harbour.

Then, as to the silt, Mr. Walker agreed, to a certain extent, with Captain Washington, that a portion was held in suspension, but only for a short distance from the shore. The appearance of discoloration arose, most probably, from the quantity of chalk débris which abounded along the shore; but it was so light, that he believed nearly all the silt brought in by the flood, was washed away by the ebb in heavy weather, and it would be found at Dover, as at Kingstown, that no detrimental deposit of silt would occur. This was the case at Plymouth, where the fears of deposit were proved to be groundless.

A great portion of the examination of the witnesses before the Commissioners, had turned upon the preference to be accorded to vertical walls, or to slopes. Now Mr. Walker submitted, that each would answer the purpose, and had its comparative advantages, and that a Civil Engineer should not adopt either form, as generally and indiscriminately applicable for all situations; but should use either, as his judgment of locality, and of the prices and quality of materials at the place dictated. In the decision, many points should be considered. Mr. Walker's general predilection was in favour of a long slope, because, from experience, he found, that it offered less direct opposition to the waves. For instance, the same sea which rolled harmlessly over the slope at the Plymouth Breakwater, would strike the buttress with great force, and rise to a considerable height.

The comparative expense of the two kinds of structure also required to be considered. At Dover, a slope would cost much more than a vertical wall, because of the deficiency of proper hard materials. The same stone, which at Portland would cost three, or four shillings per cube yard, could not be procured at Dover under three, or four times that amount. The Government had, therefore, resolved to face the Dover Pier with hard ashlar stone, and to build it nearly upright. In this position also, a long slope would not have been applicable, because vessels could not safely come alongside in rough weather, to load and unload their cargoes, or passengers. 
At the Channel Islands the quality of the granite was generally acknowledged to be excellent, yet Mr. Walker's first step was to open quarries, in order to ascertain precisely the quality and price of the materials. He then recommended a long slope, with a wall sloping at an angle of one to one at the top, because the cost of a vertical wall would have been greater, on account of the more careful workmanship required for its construction, and the materials being ill suited for squared work.

Time would not permit him to multiply examples, of which there were plenty existing, to show that no Civil Engineer of eminence attached himself exclusively to one form of construction; but that he adapted his practice to the locality, applicability, cost, time of execution, and numerons other points, familiar to every one having the direction of large works.

Sir John Rennie begged, in the first place, in common with every Member of the Institution, to thank the Noble Lord for thus coming among the Engineers and taking part in their discussions, as well as for his Lordship's very interesting Paper upon Harbours of Refuge, in which the arguments for and against the contemplated sites and modes of construction, were so fairly considered. He was very sorry, therefore, to be unable to agree with the conclusions arrived at by his Lordship, from the documents to which he had access. To pass in review the whole of the subjects which had been treated of, would be foreign to his purpose, and might, he feared, be found rather tedious. 'Sir John would, therefore, confine his remarks chiefly to those parts of the Paper relating to the works in which his father and himself had been concerned, and upon which, he regretted to find, that the Noble Lord had not obtained more accurate information, but which Sir John Rennie would have had the greatest pleasure in supplying; and he felt convinced, that if such information had been communicated, his Lordship would not have made the remarks upon those works which were contained in the Paper.

As regarded Captain Vetch's plan for converting the Brake Sands into a breakwater, Sir John Rennie thought, that the idea was entertained by him about the same time, if not previously, and was explained in his Report to the Trustees of Ramsgate Harbour on the 15th of March, 1842.

As regarded Plymouth Breakwater; notwithstanding all that had been said against it, he was prepared to maintain, that whether as regarded the plan, or the mode of carrying it into effect, nothing could have been more successful. Originally, Plymouth Breakwater was only intended to have been raised to about the level of 
half tide, because it was conceived, that sufficient protection would thereby have been given to the anchorage in the Sound, and it was not deemed advisable to incur greater expense, than was absolutely necessary, or to run any risk of injuring the harbour in other respects. Accordingly, the original quantity of rubble was calculated at 2,000,000 tons, exclusive of the subsidiary pier at Point, and the masonry at $1,353,500$ cubic feet, at the estimated cost of $\mathfrak{1} 1,059,674$, exclusive of the pier at Andurn Point; but, as the work proceeded, the original calculations were proved to be so well founded, that more protection could be given to the anchorage in the Sound, without interfering with the general convenience of the harbour in other respects; it was, therefore, determined to raise the breakwater from the level of half tide, according to the original plan, to the height of 2 feet above high water, of average spring tides. This departure from the original plan greatly increased the extent of the whole work, and induced corresponding alterations in the form and quantities of the materials. It also augmented the cost in the same degree; but, making due allowance for this, it would be found, that the breakwater would still cost $£ 290,000$ less than the original estimate. The mode of construction adopted, after mature consideration, was the rubble system, which consisted in employing only angular blocks of stone of different sizes, as raised from the quarries, and depositing them by their own gravity in the line of the intended breakwater, leaving the action of the sea to consolidate and dispose of them, according to such a form, or angle of repose, as might be best adapted to resist the waves during storms. Such being the principle of construction adopted, it followed as a necessary consequence, that the exterior form of the rubble mass would, from time to time, be subject to alterations, until the desired angle of repose had been obtained; in fact, the waves themselves, as so well expressed by the late Mr. Rennie, became the principal artificers, or masons, in working the deposited materials into a proper form; and a considerable portion of the workmanship, which otherwise must have been executed artificially, was effected by the waves themselves. All the changes of form which inevitably followed, during the execution of the work, far from being disasters, as they had been improperly termed, in the Report of the Refuge Harbour Commissioners, had been foreseen and calculated upon, in laying down the original plan and estimate. This had been repeatedly explained to the Admiralty, both by Mr. Rennie and Mr. Whidby, in their reports upon the progress of the works.

As regarded the changes of form; by referring to the various sections taken at the time, it would be seen, that the effects of what 
had been termed failures, or disasters, were merely confined to the surface of the exterior, or sea slope, extending from a few feet below the level of low water of spring tides upwards, and the only result was, that the surplus rubble was transferred from the sea to the land side; thus rendering the angle of the sea slope rather more than five to one, and reducing the land slope to an inclination of two to one, and in that state the rubble generally remained quiescent. The rubble foreshore was added on the outside, at the recommendation of Messrs. Chapman, Jessop, G. Rennie, and Sir John Rennie, and the addition was approved of afterwards by $\mathrm{Mr}$. Telford. In fact, it was a necessary consequence of raising the whole work from half tide to above high water of spring tides. The casing of masonry was at length added, for the purpose of preventing the occasional changes on the surface, before alluded to, and of giving a finished appearance to the whole work; although, as regarded the great object of the breakwater, in affording protection to the Sound, that had long been answered, and the additional cut-stone masonry was not essential.

With regard to the observation, that the rubble was not sufficiently solid, nearly the same answer might be given; that the alterations of form had been almost entirely superficial, and were confined to the exterior slope; that the main mass, or body of the work, had not been disturbed, and that no blocks had been removed from the line of the work, as was proved by sweeping the Sound with a diving-bell, in order to set at rest the doubts and observations of those who entertained a contrary opinion; so that no object but increased expense would have been obtained, in rendering the main mass more solid. Again, quantities of smaller materials, as well as certain portions of quarry rubbish, which were sufficiently hard, were used, according to the original specifications of the late Mr. Rennie, and of Sir John Rennie, where they were necessary, both in laying the masonry for the foundation of the lighthouse, as well as in preparing that for the masonry casing, on other parts of the work. The rubble which it was necessary to remove, in order to prepare for the masonry, was subsequently found to be so solid, that it could only be worked out as from a quarry.

As regarded the occasional displacement of portions of the masonry casing; that must be expected in all large works, and the fact of its having occurred formed no real objection to the system adopted, and whenever, by duration of time, the subjacent rubble had become consolidated, and the foreshore was properly kept up, and the cut-stone masonry well laid, it had been found to stand well. 
In several places Sir John Rennie had tried vent-holes, for allowing the air to escape from beneath the masonry casing; but when the rubble was sufficiently solid, they were unnecessary.

If the plan, now advocated by the Commissioners, of constructing a solid vertical wall from the bottom of the sea had been adopted, the almost endless time and cost would have rendered it, to a certain extent, impracticable; but even supposing, that it had been attempted, the expense of the repairs would have been far greater than that of the system adopted. Indeed, the almost vertical wall of solid masonry, built upon the top of the rubble-work, which had failed, was constructed by Mr. Whidby, against Sir John Rennie's advice. It was also disapproved of by the late Mr. Telford, Mr. Chapman, Mr. Jessop, and Mr. G. Rennie.

By the plan adopted, considerable protection was afforded to the Sound, within eighteen months after the commencement of the work, and within twelve years the whole anchorage was rendered safe, which, considering the mass of work, executed in such an exposed situation, was certainly a very small period of time, and could not. have been effected by any other plan. By making allowance for the additional quantity of workmanship and materials necessary for raising the Breakwater so much higher than was originally intended, it would be seen, that the actual cost of the work was $£ 290,000$ below the original estimate.

Sir John Rennie would not trespass further upon the patience of the members; but for any further remarks upon the Plymouth Breakwater, he begged to refer to his published account of that national work, in which, he believed, that satisfactory answers would be found for every objection that could be raised.*

With respect to Kingstown Harbour, nothing could be more erroneous than the reported observation of Colonel Jones, "that notwithstanding an expenditure of $£ 800,000$, it was as insecure as before." The same system had been adopted there as at Plymouth, and had as completely answered, when the work was properly carried into effect. If the system of building a vertical wall of masonry had been adopted, the time of execution and the expense of the work, would both have been enormously increased, and the cost of the repairs would have been augmented.

The allusion to this subject induced Sir John Rennie to make a few passing remarks upon certain changes which had been made in

* Vide An Historical, Practical, and Theoretical Account of the Breakwater in Plymouth Sound. By Sir John Rennie, F.R.S., F.A.S., F.G.S., Pres. Inst. C.E., folio, plates. London, 1847 . 
the original design of Kingstown Harbour, as it was left by the late Mr. Rennie. These, he must contend, had materially detracted from the benefits which would otherwise have been conferred. They were made under the direction of the Commissioners of Public Works, when Sir John Burgoyne was Chairman of the Board. Sir John Rennie had pointed out the objections to them at the time, and the result had justified his anticipations. In the first place, the entrance had been altered, so that during easterly gales such a heavy sea set in, that vessels lying at anchor in the harbour were greatly and unnecessarily exposed, and several had actually been driven ashore, and wrecked. Secondly, a vertical wall of masonry had been projected a considerable distance into the centre of the harbour, in front of the entrance, for the purpose of forming a landingjetty for the packets. The line of shore, in that particular part of the harbour, was, if anything, too much anvanced, before the erection of the jetty, or wall before mentioned. The sloping form of the rocks, however, served in some degree to check and disperse the waves; but the new wall, by projecting further into the harbour, from its vertical form, exposed as it was to the impact of the waves, from the altered entrance, created such agitation in that important part of the barbour, that the packets experienced the greatest difficulty in lying alongside it, during heavy easterly gales. Thus the very object of the wall, which was constructed at a very great expense, had been to a great extent defeated, at the very time when it was most required. Thirdly, the old harbour of Dunleary was expressly included in the original design, as it contained the only portion of flat sloping shore where disabled vessels could run and beach upon; it served moreover as an excellent place, where any waves which might enter the harbour during easterly gales conld expend themselves, and thus tend to tranquillize the other parts of the harbour; it was, therefore, considered of the utmost importance, that it should be preserved; but, notwithstanding these advantages, the Dublin and Kingstown Railway Company had been permitted to construct, across that part of the harbour, a solid embankment, at a slope of about two to one, thus abridging the valuable space, and at the same time materially increasing the general agitation within. This might readily have been avoided, by directing the railway along the shore, or even carrying it upon an open viaduct, which, by means of Mitchell's screw-piles, or other method, would have been very practicable, and not at all expensive. The whole of these alterations were, in Sir John Rennie's opinion, very injudicious, and had materially injured the harbour. This was the more to be lamented, because the whole of the objects, intended to 
have been gained by the alterations, might have been obtained in a more effectual manner without creating the evils which had been alluded to.

Then, as regarded Howth, the flat rubble slope had answered very well, and it still remained to be proved, whether Howth was not the proper station for the packets. As to the harbour of Donaghadee, the flat slope there had also stood very well; and it was only at the spot where the vertical masonry wall of the east pier head, (which was necessary in that small harbour,) was joined into the flat slope, that a few of the rubble blocks were displaced, before the glacis was quite finished; these had since been replaced, and the rubble glacis, after being paved at a trifling expense, had stood well. It should be recollected also, that the Harbour of Donaghadee had been completed for $£ 15,000$ below the original estimate, and that sum was devoted to constructing the east pier 10 feet wider than had been originally intended.

As to Ardglass : the stone of which the pier was built, was of a soft slaty schistose nature, and would not resist the effect of the waves; this he had pointed out at the time, and had recommended the employment of other stone, which was better adapted for the purpose. His advice, however, was not followed; the work, moreover, was left in an unfinished state, exposed to the full effect of storms, and Sir John Rennie had expressly pointed out, in writing, that unless it was finished in a proper manner, it would not stand; but this was not attended to, and the natural consequence was, as had been stated by the Noble Lord, that it was considerably injured.

With respect to Portrush: that harbour was designed and constructed by Sir John Rennie. Both piers were carried out to their full extent, in about eighteen months, by depositing blocks of rubble. The establishment was then broken up, and, instead of feeding the slopes of the piers, from time to time, with fresh rubble, as fast as it was drawn down by the waves, in the process of consolidation, and until it had obtained the requisite angle of repose, nothing was ever done; consequently, the slopes could not be expected to remain permanent. In fact, the work was never finished; but, after all, what was the result? A harbour, having two piers, with an entrance between them of about 13 feet deep, at low water of spring tides, enclosing a space of five imperial acres, at low water, was erected in a most exposed situation, and so far completed, for the small sum of about $£ 16,000$; and, according to the Report of Messrs. Stevenson (of Edinburgh), a further sum of only $\mathcal{L} 5,000$ was required to complete it; in fact, Sir John Rennie did 
not know a case, where so much accommodation had been obtained for so small a sum.

He must contend, that this harbour was a most complete answer to the objections against the rubble system; for had a vertical wall of masonry system been adopted, the work would have cost at least four times the amount actually expended, and would not have answered so well ; in fact, the construction of the harbour could not have been attempted.

With regard to Dunmore : that pier was built of soft bad sandstone, originally, Sir John Rennie believed, with a vertical wall of masonry, but it failed; a glacis, or flat sloping wall, was then added to the outside; that, although not well executed, had been more effective than the original verticul wall, and, therefore, that pier should rather be quoted as an example in favour of the inclined, or flat slope, instead of being adduced as an argument against it.

With regard to the breakwater at Cherbourg: the failures there arose from the rubble, originally employed, being composed of blocks of too small dimensions. As soon, however, as materials of proper sizes were employed, the rubble system answered very well ; a vertical wall of masonry had subsequently been raised upon the top of it, and it remained to be proved, how far it would answer. It now required constant protection, by the addition of rubble, placed outside, without which, it would not stand ; and it was stated, that during heavy gales, the waves broke so furiously against the upright wall, that it was impossible to approach, or to walk upon it, although it was 10 feet, or 12 feet above the level of high water of spring tides. Considerable alterations were still requisite, before it could be made to answer the intended object.

With respect to the contemplated project of making a refuge harbour in Dover Bay: Sir John Rennie had explained his views on the subject so fully, in his Report to the Admiralty, ${ }^{*}$ that he could not add anything further to them. In fact, the more he considered the Report of the Tidal Harbour Commissioners, upon that subject, the more he was inclined to adhere to the opinions expressed in his Report. He believed, that if ever the plan was carried out to the extent contemplated by the Commissioners, the cost would, certainly, not be less than he had stated; but would, probably, greatly exceed it. Mr. Walker had stated, that rubble from the Channel Islands, or from Portland, would be so very expensive, that a different system of construction must be adopted. Now it must be

* Vide Minutes of Evidence on the Harbour of Refuge to be constructed in Dover Bay. 
recollected, that the argument which applied to the rubble, would apply with almost equal effect to the masonry; and that a cubic yard of the latter would cost very much more than a cubic yard of the former.*

Sir John Rennie thought, the protest of Sir Howard Douglas was an extremely able production, and reflected the highest credit upon that distinguished officer. The arguments adduced by him, both as to theory and practice, appeared, for the most part, unanswerable. $\dagger$

Sir William Symonds' protest, though short, contained much sound sense, particularly his observations relative to the 'gregale,' during northerly gales, upon the perpendicular rocks forming the entrance to Malta Harbour. $\ddagger$ Sir John Rennie had, himself, witnessed their effect in March, 1826; when large portions of the vertical masonry walls of the great bastion of Ricogali, were undermined and blown up by the waves, and were only restored at great cost.

He apologized for having occupied so much of the time of the meeting, but he trusted, that he had, in some degree, removed the objections to the rubble system, and had proved that the cases quoted by the Noble Lord, in favour of the vertical walls told completely in the opposite direction.

Sir John Rennie did not, however, mean to assert that there might not be many cases, where nearly vertical masonry could be judiciously employed; in fact, he had adopted the system in several instances, and the piers so constructed had completely answered their object.

He could not conclude without again thanking the Noble Lord for his valuable Paper, and expressing the hope, (in which he was sure the whole of the Institution would join,) that his Lordship would continue to bring Papers before them, and that they should have frequent opportunities of discussing the great engineering works of Great Britain.

Mr. Rendel, V.P., joined his acknowledgments to those of the preceding speakers, for the excellent Paper that had been read, and which would do honour to any Engineer. He would only occupy the time of the meeting by justifying the accuracy of his estimate of the vacuity in the Plymouth Breakwater, and would merely state

* Vide Reports and Plans for a proposed Harbour in Dover Bay, No. 4. London, 1845.

$\dagger$ Vide Papers relating to the Harbour of Refuge Commission of 1846, on the several modes of construction referred to the Commission for their opinion, pp. 3-48.

$\ddagger$ Vide ditto, ditto, pp. 1-3. 
how he arrived at the conclusions he had expressed elsewhere. He ascertained the absolute cubic contents of the Breakwater, and the total weight of stone delivered upon it; then, as it was well known, that 13 eubic feet of Plymouth marble weighed one ton, and he found that weight was made to occupy 19 feet, or 20 feet of cubic space, he was justified in drawing the conclusion as to the amount of vacuity. His opinion was further strengthened, by seeing the heaps of small stone left behind in quarrying the material ; and he must cuntend, that a greater quantity of small stone would have materially assisted in consolidating the structure, if it had been employed with the larger blocks, so as to have filled up the interstices.

The EARL of Lovelace expressed his thanks to the meeting for the attention given to his Paper, to Mr. Manby, the Secretary, for the assistance he had rendered in its production, and for the excellent spirit with which the apparent strictures had been received. The members must be aware that the Blue-Books were the authorities whence his information had been drawn, and he was gratified, that his observations should have been the means of eliciting such complete refutations, to many of the statements he had extracted. Sir John Rennie's explanations had generally disposed of the objections that had been raised, and he now fully appreciated the force of the arguments against adopting any given form of sea-defences for all situations.

He was not at all aware, and had never seen it stated, that the original design for the Plymouth Breakwater only contemplated its reaching up to half-tide level; that explained in a great degree the increased expense, and it was not to be wondered at, that during the progress of the works, it had been considered necessary to finish them, in a manner which was scarcely contemplated at the commencement.

He would not further occupy the time of the meeting, but he could not sit down without alluding to Mr. Walker's remarks, as to Engineers not being raised to the Peerage, and he would remind him, that his late position of President of the Institution of Civil Engineers, was one of which he might justly be prouder than of any Peerage, hereditary, or created, for he had presided over a body of men, whose works, like the Pyramids of Egypt, or the Temples of Dendera, would survive all record of their designer, and even of the language of the time of their construction. And when he saw the ports and harbours, the general improvement of the coast and rivers, the tunnel beneath the Thames, the suspension and tubular bridges spanning arms of the sea, the apertures pierced through 
mountains, for the convenience of the commerce and traffic of the country, and the wonderful inventions and improvements in all branches of Science and the Arts, he thought the Engineer might, on the completion of each of the stupendous works which characterized the present time, use with pride the words of the poet,*-

Jamque opus exegi, quod non Jovis ira, nec ignes,

Nec poterit ferrum, nec edax abolere vetustas.

And even addnomenque erit indelebile nostrum.

Major-General PAsLey said, that his predilection had been in favour of long slopes for sea walls and defences, until he heard the Paper by Colonel Harry D. Jones in 1842. $†$ The arguments and examples there given, induced him to make further researches, and he became a convert to the theory of vertical walls in deep water. The duration of the Edystone and Bell Rock Lighthouses, was a strong argument in favour of the forms there employed, and the statement he had made on a recent occasion, $\ddagger$ relative to the walls on the South Devon Railway, might be also used as an argument. The majority of the Commissioners appeared to be in favour of the vertical form, after hearing the evidence of all the best authorities on both sides of the question.

After the form was settled, the next questions appeared to be, the materials of which the defences should be composed, and the method of building. General Pasley was convinced, that blocks of concrete, formed of good hydraulic lime, or cement, and laid from diving-bells, might be advantageously used nearly up to low-water mark, and above that line, granite should be employed. The motion of the waves, even in the heaviest weather, did not extend deeper than a few feet from the surface of low-water mark.

Mr. J. Murray said, it was stated by writers on physics, that if the depth of water was sufficient to allow the waves to oscillate, they could have no progressive motion : each wave being kept in its place by the action of the others around it.

Hence the existence of coral reefs in deep seas, where it might be supposed, that they could not resist the shocks to which they were exposed. These reefs opposed a nearly perpendicular surface to the force of the waves; their windward sides having sand and large masses of coral thrown up by the breakers, which were said greatly to exceed those on our shores.

* Vide Ovidii Metamorph., lib. xq.

+ Vide Minutes of Proceedings Inst. C.E., 1842, vol. ii. p. 124.

† Vide Minutes of Proceedings Inst. C.E., 1848, rol. vii. p. 193. 
The coast of Norway, which was in general bold and steep, with a depth of water close to the rock of from 100 to 400 fathoms, possessed a striking peculiarity in its configuration, inasmuch as it had an outer and an inner line of coast; the latter was the shore of the mainland, and the former was formed by a countless number of rocky islets of all dimensions; within was smooth and deep water, even when the sea was strongly agitated without. The rocks of gneiss and mica schist were usually hard, and were slowly decomposed, yet they had been cut up by the long swell of the Atlantic, which struck the rocky coast with violence: and thus the peculiar fiords and narrow channels had been formed.

The western coasts of Ireland and Scotland were somewhat analogous to that of Norway; bold, rocky, and deeply indented with creeks and inlets. Soundings, however, were met with on approaching the land, and this shelving shore prevented, or retarded the oscillation, and the deep-water waves, not being balanced by those in the shallower water, acquired a progressive motion.

Skerryvore Lighthouse was situated on an exposed rock on the western coast of Scotland, but within the line of soundings of 60 fathoms; and there some observations had been made by Mr. Alan Stevenson, on the strength of the waves. Although Mr. Murray was not quite convinced of the accuracy of the dynamometer employed, yet considerable reliance might, he thought, be placed on it. The greatest result recorded, was a pressure of $6,083 \mathrm{lbs}$. on a square foot ; the average results of the six winter months of 1843 and 1844 being equal to $2,086 \mathrm{lbs}$. per square foot. Now, according to Leslie,* this made the velocity of the waves in a gale at Skerryvore to be 55 miles an hour, and in the ordinary seasons of winter, 32 miles per hour.

The line of soundings of 60 fathoms, extended across the mouth of the British Channel, from Brest to the Scilly Isles, gradually shoaling to the Straits of Dover, where the greatest depth did not exceed 20 fathoms. In this comparatively shoal water, the tidal waves must be those of progression, and were consequently percussive; therefore, obstacles exposed to them, like breakwaters, must be made sufficiently strong to resist their impact.

As instances of injury sustained by nearly perpendicular walls, he must state, that the sea sometimes struck the new North Pier Head at Sunderland, with great violence, and the old Pier Ilead, built about the year 1800 , adjacent to the Lighthouse, though tolerably well constructed, was destroyed during a storm.

*Vide Leslie's Elements of Natural Philosophy. 
In 1843 a breach of 40 feet in width was made, in the nearly perpendicular pier-head of Port Patrick Harbour, at a depth of from 20 feet to 25 feet below high water, leaving the foundation of the Lighthouse exposed and in great jeopardy.

At Whitehaven Pier the waves struck it laterally with great violence, and were thrown over it in the form of a clear sheet of water. Such was also the case at the Cobb Wall at Lyme Regis, although it was greatly protected by an extent of shelving rocks.

A very heavy sea struck upon the Chesil Bank, which extended from the Isle of Portland westward for a distance of upwards of seventeen miles. The pebbles of which it was formed, were generally about the size of an egg, at the Isle of Portland, while at Bridport, (to the westward,) they were scarcely larger than peas. Its section was also peculiar. And from the outline, as also from that of the shore at Madras, it was evident, that the tendency of the action of the waves, in retreating, was to form nearly regular steps. Much of the stability of the Plymouth Breakwater was due to the wide berm, or benching, on its seaward side.

While constructing the rubble glacis, both at the south and north piers of Sunderland and at Warkworth, almost every separate stone was laid by the action of the waves at a regular slope, nearly approaching $45^{\circ}$ with the horizon. The masses of magnesian limestone which were now being deposited by the action of the waves on the south rocks at Sunderland, were lifted by the sea and laid in a similar manner, and also in a form approaching to regular steps. Mr. Murray was, therefore, of opinion, that the sea face of an exposed breakwater in Dover Bay ought to have a stepped sloping glacis, terminating with a cycloidal curved parapet.

It had been stated by Engineers, and was believed by many, that the agitation of the sea was only felt at a little distance below the surface.

Brémontier said, that the agitation in storms, extended in many cases to very great depths; on the sandbank of Newfoundland it descended even to 60 fathoms.

To the south of the Cape of Good Hope the sea was broken, where the depth was more than 100 fathoms.

M. Virla found the velocity, in great waves of 130 feet in length, to be 66 feet per second, or 45 miles an hour, and the vertical depth of the agitation to be 54 fathoms.

M. Viennois had made some observations on wades, in the Bay of Biscay, and found, that the depth of the agitation, during storms, was from 164 fathoms to 212 fathoms, and that the velocity of the oscillation was from 30 miles to 45 miles per hour. 
With these facts in evidence, it would surely be wise to pause before placing a breakwater with vertical sides in Dover Bay.

Major-General PAsLex doubted whether the French Engineers, whose authority had been quoted, had ever descended in a divingbell, or a diving-helmet; and in default of evidence to that effect, he must be permitted to reject their opinions.

Mr. J. Murray said, that he had frequently descended in the diving-bell, and although he knew, that, under ordinary circumstances, the agitation of light winds at the surface, did not influence the greater depths, yet he had, on the contrary, found considerable agitation below, when the surface was apparently tranquil. Whenever the bell was heaved and became wet inside, a storm invariably followed. This he attributed to the movement of the great body of water in the Atlantic, forcing up the under-current.

Major-General PASLEY attributed the unsteadiness of diving-bells generally to their improper form; he never could use them advantageously, until he adapted pointed ends to them. In shallow water they might be used, but in deep water, men in diving-helmets could do much better work.

Sir John Rennie reverted to the facts of the construction of the Plymouth Breakwater, and, as a passing reply to General Pasley, Sir John was of opinion, not only that diving-bells were preferable, but that divers in helmets would not have been able to do the work at all.

It was considered desirable to construct the Breakwater with the utmost speed, and accordingly, in eighteen months from the date of its commencement, it afforded shelter under its lee, to a ship of one hundred and twenty guns. Now if the sections of the Breakwater, taken at many different periods, were examined,* it would be seen, that the sea had only taken away portions of the covering, and carried the materials over to the leeward side, giving the seaward slope, that inclination due to the action it had to support; but the blocks were not conveyed to any considerable distance.

If the whole history of the Breakwater was considered, as given in his recent account of it, it would be perceived, that instead of exceeding the estimate, it had been completed within the calculated cost. The term "disastrous" could not, therefore, he contended, be correetly applied to that work.

Mr. J. Scotr Russell thought, that Lord Lovelace had done good service, not only in producing so interesting a Paper, but in eliciting opinions from the eminent Engineers who had spoken upon

* Vide Rennie's Plymouth Breakwater, Plates 13 to 17, and 20 to 22. 
it. Mr. Russell thought, that neither vertical walls, nor sloping seadefences, should be considered irrespective of the three great questions, of the position of the work, the nature of the material to be employed, and the total cost. Now as to the amount of force stated to be acting against the Edystone and the Bell Rock; if their form and mode of construction, by bonding and rendering them almost monolithic, was to be adopted for sea-defences, half-a-dozen such masses would cost as much as the Plymouth Breakwater; that kind of construction was, therefore, evidently inappropriate for sea-defences, and that which apparently offered the greatest facilities, under ordinary circumstances, was that which had been adopted at the Plymouth Breakwater, where the weight and consistency of the mass formed its safeguard.

From what had been stated, it might be inferred, that a vertical wall would deflect the waves without breaking, and that a smaller quantity of material was employed; but as the foundations required to be well laid, at considerable depth, great care was necessary in the construction, and superior materials must be employed, therefore the cost would, in ordinary positions, be enhanced.

Sloping sea-defences were liable to run into extremes, either in having too gentle, or too rapid a face towards the sea. If large blocks of stone were at hand, with smaller materials to fill up the interstices, it was easy to place them, in due proportion, at an angle of $45^{\circ}$, which was the best inclination; because if the slope was flatter, a portion of the advantage of the superincumbent weight, or pressure, of the upper stones was lost, and on a nearer approach to the vertical, if the lower stones were drawn out, by the retiring wave, the upper courses fell. In a vertical wall the greatest effect of weight was obtained, and if the foundation did not give way, the faces of the stones being smooth, and the joints well filled in, it would stand ; but the angle of $45^{\circ}$ must, he contended, be considered, generally, as that which offered the greatest amount of advantage under ordinary circumstances.

Mr. WALKER confirmed Mr. Russell's views; there could not, in practice, be any general rule; all descriptions of works had failed, and would fail again, under particular circumstances. The forms of all sea-defences must be adapted to the various considerations named by Mr. Russell, and must vary with them. For instance, Mr. Walker was now constructing a vertical wall, a long slope, and a sea-defence at an angle of $45^{\circ}$, in three different positions, and he saw no reason to doubt the success of all the three; in fact, they would stand, or fall, as they were well, or ill constructed, and their [1848.] 
forms were well, or ill adapted to resist the forces to which they were opposed.

If a form like that of the Chesil Bank was adopted at Dover, the work would never be finished, with any ordinary means, or at any reasonable expense, as the material would cost nearly three times as much as that used at Plymouth, and unless a whole fleet was employed to convey the stones, the necessary quantity could not be obtained; therefore the pier that had been commenced was nearly vertical, particularly as it was necessary, that vessels should come alongside to load and discharge their cargoes.

Mr. Walker was of opinion, that however good, or successful any work might be, it should not be blindly used as an argument, or as a precedent for any other construction; it was the business of the Civil Engineer to adapt his design to the locality, the material, and the cost., and to use the experience he had acquired, or the examples set him by others, to prevent his falling into errors. Such also was the great use of the discussions at the Institution, and he would conclude by again thanking the Earl of Lovelace for bringing the subject before the Members, and trusted, that during the next Session his Lordship would be very frequently found among the Engineers, and contributing Papers to the Institution.

\section{Lambert's Flexible Diaphragm Water-Valves.}

After the Meeting, Mr. Lambert exhibited and described his flexible diaphragm water-valves. Two flexible diaphragms, $c$ and $c x$, are used, confined at the edges by screws $i$, the centre portion being moveable and connected by a spindle, so that they move simultaneously when acted upon by the lever $e$.

The chief novelty of the invention consists in the application of the lower diaphragm $c x$ as a surface to be pressed upon by the column of water in the supply-pipe, and thus aid in keeping the valve tight, by holding the upper diaphragm $c$ to its seating. The area of $c x$ being greater than the area of the opening, or outlet closed by $c$, it follows, that as soon as the diaphragm $c$ is pressed upon, the valve-seating, by means of the lever $e$, assisted by the screw in the cover $d$, (or otherwise, is there held by the excess of pressure upon the area $c x$, and thus by adapting the area of $c x$ to the height of the column of water, it may be made to open as easily under a pressure of 500 feet, as of 50 feet. The upper diaphragm $c$, in addition to its making the valve-joint, serves the purpose of a 